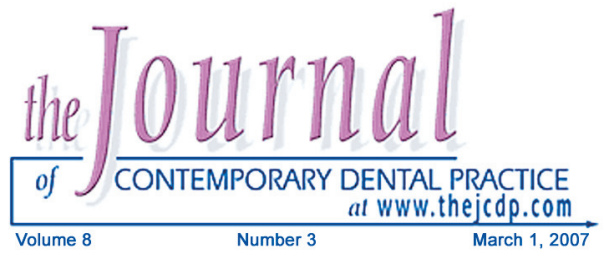

\title{
Attitudes of Romanian Dental Students Towards Tobacco and Alcohol
}

\section{Alexandrina L. Dumitrescu, DDS, PhD}

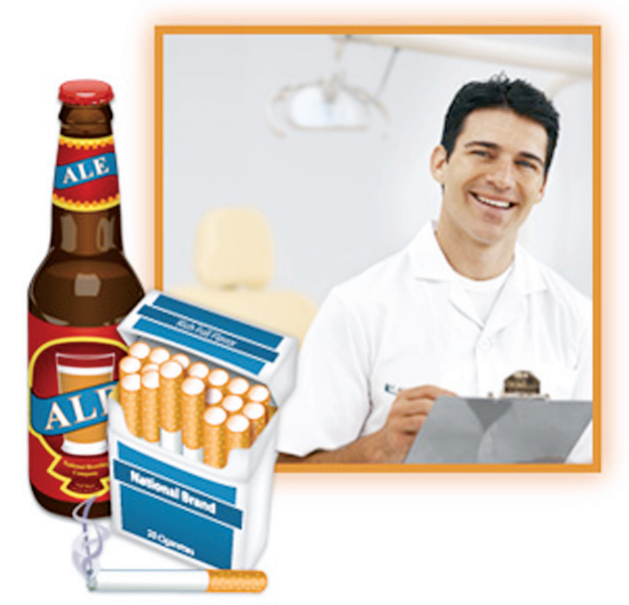

\section{Abstract}

Aim: The aim of this study was to assess smoking and alcohol use in male and female Romanian dental students and to compare this with different levels of education.

Methods and Materials: A total of 315 questionnaires were distributed to male and female dental students (first to sixth year students).

Results: Among the 315 respondents, $37.33 \%$ were smokers and $71.04 \%$ o f students used alcohol on a regular basis. Overall, there was a 30-day smoking prevalence of $32.47 \%$. Among those who smoked daily, $24 \%$ were sixth year students and only $10 \%$ were first year. The average number of cigarettes smoked was thirteen cigarettes per day with males smoking more than females $(p<0.0001)$. The average number of years as a smoker was five years, with fifth and sixth year students smoking longer than others $(p<0.001)$. The average age when students started to smoke was 17.15 years. Statistically significant differences were observed between genders related to alcohol drinking $(p<0.0001)$. Significant linear relationships were shown between smoking and alcohol consumption $\left(r^{2}=0.47, p<0.0001\right)$.

Conclusion: There was a clear difference in smoking and alcohol consumption between groups of Romanian dental students.

Keywords: Romania, dental students, tobacco, alcohol, education

Citation: Dumitrescu AL. Attitudes of Romanian Dental Students Towards Tobacco and Alcohol. J Contemp Dent Pract 2007 March;(8)3:064-071. 


\section{Introduction}

Tobacco represents the single most preventable cause of disease and death in the world today.

Of 260 million male deaths in the developed world between 1950 and 2000, it is estimated 50 million were due to smoking. Currently, some four million deaths per year are attributable to tobacco, and this figure is expected to rise to 8.2 million by $2020 .^{1-3}$ According to the World Health Organization (WHO), in Romania between 20022005 the total adult prevalence of smoking was $21.4 \%$ with higher values in males $(33.2 \%)$ than in females $(10.1 \%)$. ${ }^{4}$ The mean of lost years per death from smoking was 21 years. In males, smoking-attributed deaths were estimated at $20 \%$ from all causes and to $41 \%$ from all forms of cancer. ${ }^{5}$

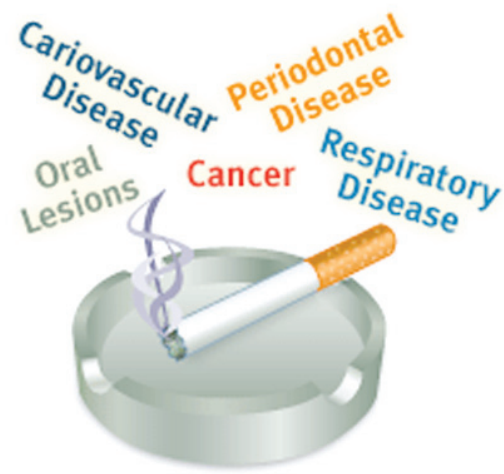

Tobacco use is associated with a wide variety of diseases including respiratory and cardiovascular diseases and cancer. The oral lesions and conditions associated with tobacco consumption are numerous. It has been estimated smoking accounts for half of all periodontal disease; $59 \%$ of oral cancer among females and 91\% among males. ${ }^{1,6}$

The dental team can play an effective role in the creation of tobacco-free patients as well as their communities through participation in community and political action and by counseling their patients to quit. ${ }^{7-10}$ Maintaining a smokefree environment is important. Although much published research has been concerned with how to motivate the patient, little attention has been given to the context of when and how dental students undergo attitudinal and behavioral changes with respect to their own smoking habits and alcohol consumption. ${ }^{11-12}$ The rates of tobacco and alcohol use among students are disturbing, and they suggest novel approaches are needed to augment existing prevention programs in order to reduce the prevalence of tobacco and alcohol use among young people. ${ }^{13}$

The aim of this study was to assess smoking and alcohol use in Romanian dental students and to compare them according to gender and different levels of education.

\section{Methods and Materials}

\section{Participants}

The 315 subjects of the study were first through sixth-year dental students at the University of Medicine and Pharmacy "Carol Davila" who volunteered to participate in this survey using a questionnaire assessing their cigarette smoking, alcohol use, and demographic variables. The data collection was done at the beginning of the academic year. The questionnaire was completed anonymously by students during normal class sessions. All students selected for the survey answered the questionnaire (Figure 1). Behavioral measures of smoking included the following:

1. Determination if a student ever smoked?

2. Number of cigarettes a student smoked daily.

3. Number of days a student smoked during the previous week.

4. Age when a student started to smoke.

The smoking exposure to the individual was expressed in terms of consumption as follows: ${ }^{14}$

1. The number of cigarettes consumed per day.

2. The duration of smoking in terms of the number of years a student smoked.

3. The life-time exposure in terms of the accumulated exposure over time as calculate by multiplying the daily consumption by the duration (years) and expressed as "cigaretteyears."

The behavioral measure of alcohol used included four categories (never, everyday, once a week, and once a month). Demographic variables such as age, gender, marital status, and type of accommodation were collected from all students. The mean age (SD) of dental students was 21.87 (2.49) years old. The percentage of female students was high in the sample $(68.96 \%)$. 


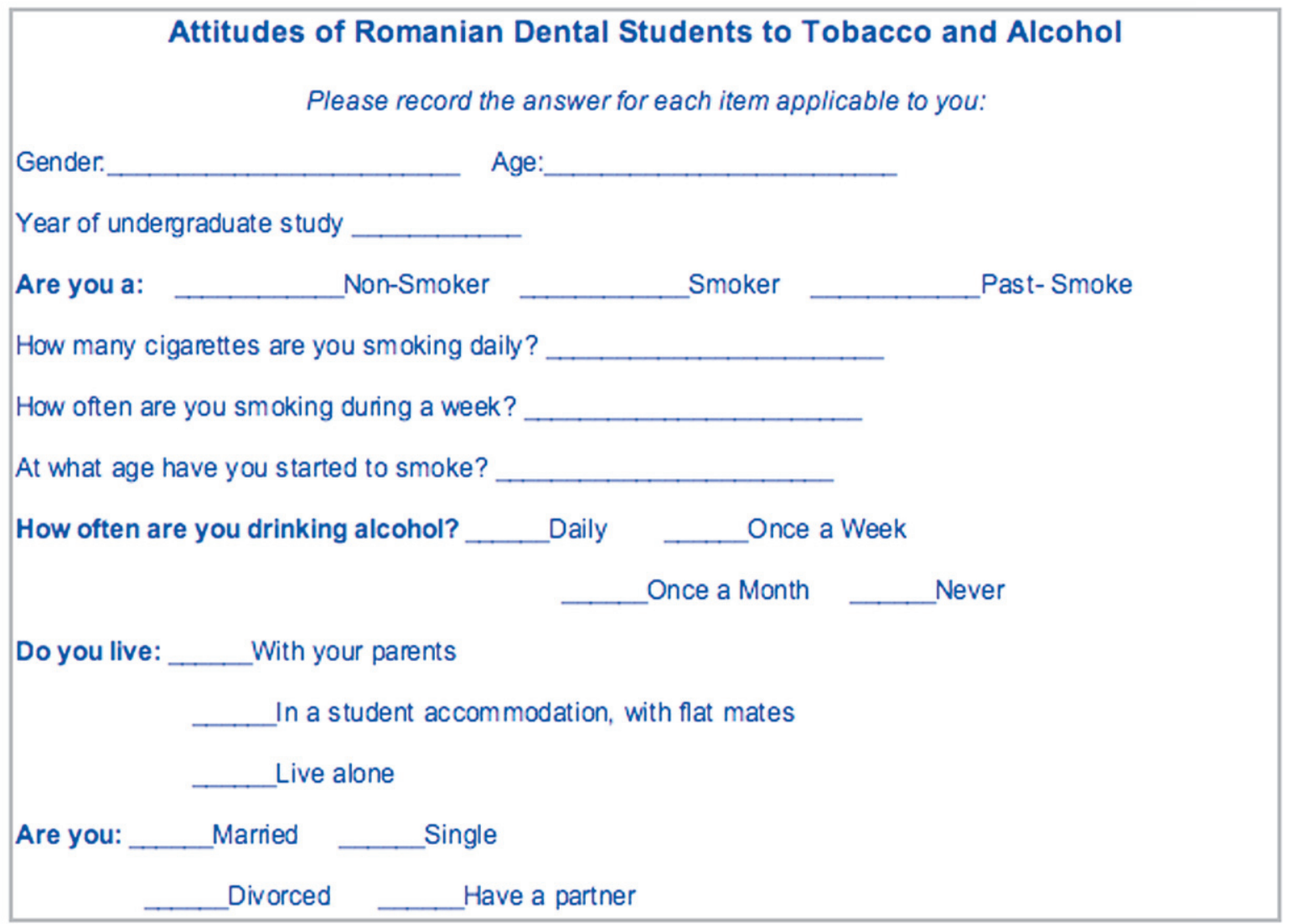

Figure 1. The questionnaire used in the study.

\section{Data Analysis}

Statistical analysis included frequency distributions, chi-square analysis, t-tests, and analysis of variance (ANOVA). Pearson correlation coefficients were calculated between behavioral assessment of tobacco and alcohol use. Alpha level was set to the conventional 0.05. Data were analyzed using SPSS 10.0 (SPSS, Inc., Chicago, IL, USA ).

\section{Results}

Table 1 presents the distribution of responders and mean age by class and gender. The number of respondents by level of dental education ranges between 47 and 62 respondents, whereas 200 female students and 90 male students participated in the study.

\section{Tobacco Use}

One in three (37.33\%) students reported smoking regularly or occasionally. Overall, there was a 30day smoking prevalence of $32.47 \%$. Among those who smoked daily, $24 \%$ were sixth year students. Only $10 \%$ were first year students suggesting regular smoking was not a characteristic among freshmen students (Table 2).

The average number of cigarettes smoked was thirteen cigarettes per day with males smoking more than females $(p<0.01)$. The average number of years as a smoker was five (5.38) years with fifth and sixth year students smoking longer than others $(p<0.001)$.

The average age when students started to smoke was 17.15 years. Of the smokers in the present study, $25.80 \%$ started to smoke before the age of 15 , and $70.96 \%$ before the age of 18 . There was not a significant difference according to gender and across years in dental school for the onset of smoking ( $p>0.05)$. Unadjusted linear regressions showed significant linear relationships between the average number of cigarettes smoked per day and the average age when students started to smoke $\left(r^{2}=0.49\right.$, $\mathrm{p}<0.0001)$. 
Table 1. Distribution of responders and mean age by class level and gender.

\begin{tabular}{|l|c|c|c|c|c|}
\hline Class & Female & Male & Unknown & Total & Mean age \pm SD \\
\hline Year 1 & 35 & 15 & 2 & 52 & $19.42 \pm 1.77$ \\
\hline Year 2 & 34 & 16 & 0 & 50 & $20.53 \pm 2.12$ \\
\hline Year 3 & 30 & 14 & 7 & 51 & $20.90 \pm 1.24$ \\
\hline Year 4 & 45 & 15 & 2 & 62 & $22.63 \pm 2.29$ \\
\hline Year 5 & 27 & 13 & 13 & 53 & $23.20 \pm 1.30$ \\
\hline Year 6 & 29 & 17 & 1 & 47 & $24.51 \pm 1.95$ \\
\hline Total & 200 & 90 & 25 & 315 & $21.87 \pm 2.49$ \\
\hline
\end{tabular}

Table 2. Percentage of subjects' answers by class level and gender.

\begin{tabular}{|c|c|c|c|c|c|c|c|c|c|c|}
\hline & & \multicolumn{6}{|c|}{ Class Level } & \multicolumn{2}{|c|}{ Gender } & Total \\
\hline & Answer & Year 1 & Year 2 & Year 3 & Year 4 & Year 5 & Year 6 & Male & Female & \\
\hline \multirow{3}{*}{$\begin{array}{l}\text { SMOKING } \\
\text { FREQUENCY }\end{array}$} & $\begin{array}{l}\text { Never } \\
\text { smoked }\end{array}$ & 71.15 & 72 & 64.58 & 57.63 & 62.74 & 46.80 & 47.73 & 68.18 & 62.66 \\
\hline & $\begin{array}{l}\text { Smoked 1-4 } \\
\text { days }\end{array}$ & 9.61 & 4 & 4. 16 & 6.78 & 3.92 & 2.12 & 6.82 & 5.05 & 4.87 \\
\hline & Everyday & 19.23 & 24 & 31.25 & 35.59 & 33.33 & 51.06 & 45.45 & 26.77 & 32.47 \\
\hline $\boldsymbol{P}$ & & \multicolumn{6}{|c|}{$\star$} & \multicolumn{2}{|c|}{$\star$} & \\
\hline \multirow{4}{*}{$\begin{array}{l}\text { ALCOHOL } \\
\text { CONSUMPTION }\end{array}$} & $\begin{array}{l}\text { Never } \\
\text { consumed }\end{array}$ & 34 & 28.57 & 29.17 & 29.31 & 34.61 & 17.39 & 10.11 & 36.12 & 28.95 \\
\hline & $\begin{array}{l}\text { Once per } \\
\text { month }\end{array}$ & 42 & 34.69 & 54.17 & 41.38 & 42.31 & 36.96 & 40.45 & 42.93 & 42.10 \\
\hline & $\begin{array}{l}\text { Once per } \\
\text { week }\end{array}$ & 24 & 32.65 & 16.67 & 29.31 & 23.08 & 41.30 & 46.07 & 20.42 & 27.63 \\
\hline & Everyday & 0 & 4.082 & 0 & 0 & 0 & 4.35 & 3.37 & 0.52 & 1.31 \\
\hline $\boldsymbol{P}$ & & \multicolumn{6}{|c|}{ NS } & \multicolumn{2}{|c|}{$\star \star \star$} & \\
\hline
\end{tabular}

Significant differences between the levels of dental education and between males and females; NS: Not significant, ${ }^{*}: p<0.05,{ }^{* *}: p<0.01,{ }^{* *}: p<0.00$

Of particular interest, only $7.43 \%$ of all students who had smoked in the past were no longer smokers.

Figure 2 shows the life-time exposure, i.e., the accumulated exposure over time as calculated by the product of daily consumption and years of duration ("cigarette-years") in dental students. Statistical significant differences were observed between fifth and sixth year dental students and other groups (years one and two) $(p<0.01)$.

\section{Alcohol Use}

The proportion of non-drinkers among students was $28.85 \%$. While very few students drank daily, $46.06 \%$ of male students and $20.42 \%$ of female students drank at least once a week. However, statistically significant differences were observed between genders $(p<0.0001)$.

Students living in university halls drank much more $(p>0.05)$ than those living at home or in their own accommodations. Significant differences were shown according to marital status with regard to excessive drinking $\left(\chi^{2}=49.25\right.$, df9, $\mathrm{p}<0.0001)$.

Trend analyses (unadjusted linear regressions) showed significant linear relationships between smoking and alcohol consumption $\left(r^{2}=0.47\right.$, $p<0.0001)$.

\section{Discussion}

Dentistry has a reputation as a demanding, stressful, technically exacting, and sometimes personally hazardous career. ${ }^{15-19}$ Scientists have examined occupational stress in undergraduate dental students and have shown the concerns of clinical students mirror those of qualified practitioners. $^{20-25}$

Several studies have documented dental students, particularly the males, report excessive alcohol consumption, widespread experimentation 


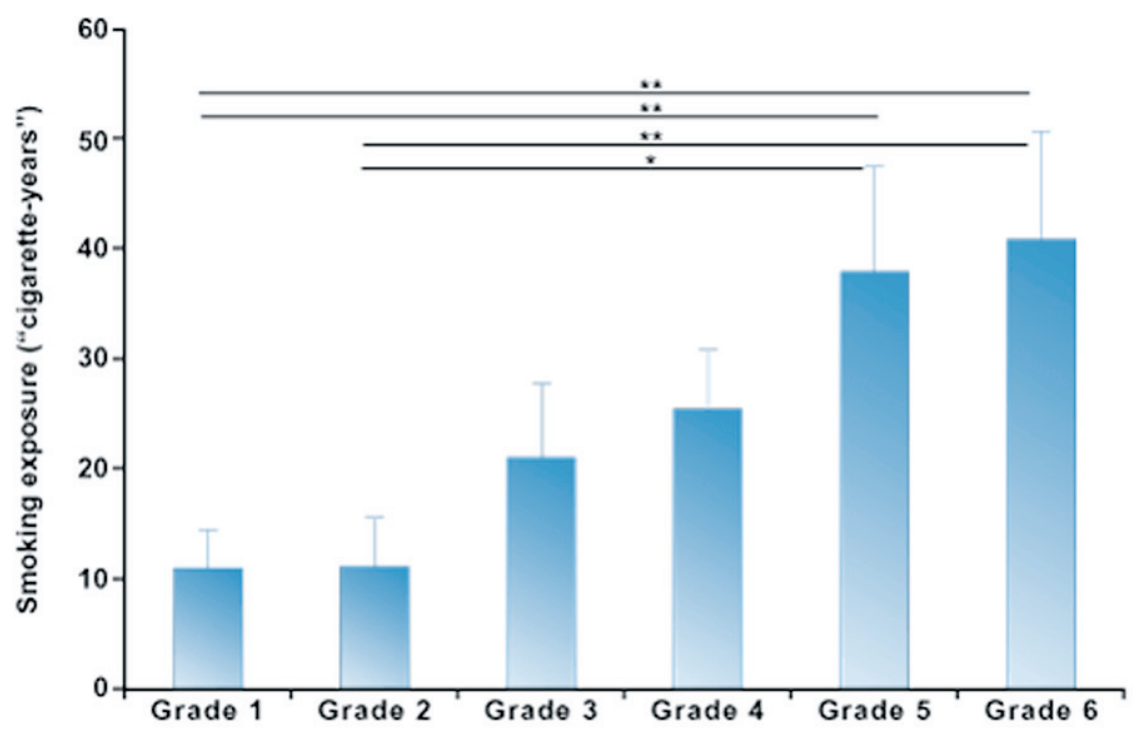

Figure 2. Dental students' smoking exposure ("cigarette-years").

with 'soft' drugs, and substantial use of other illicit substances. ${ }^{15-16}$ In a cross-sectional study in Hungary, Nagy ${ }^{26}$ reported a 30-day smoking prevalence of $35 \%$ in a university setting. Among different groups, the prevalence of smoking was $36 \%$ for science students, $34 \%$ for dental students, and $33 \%$ for medical residents. By comparison, US data revealed a 30-day smoking prevalence among undergraduates of $25 \%$. Rates of daily smoking among US medical students have been reported to range from $2 \%$ to $10 \%$. Of the adolescents sampled, 39.7\% reported ever trying a cigarette, $12.3 \%$ smoked daily, $22.2 \%$ smoked weekly, $65.5 \%$ had never tried alcohol, and $14.7 \%$ drank alcohol in the previous week. ${ }^{13}$ In Hungary the 30-day prevalence of alcohol consumption was slightly higher among science students $(80 \%)$ than among dental students $(78 \%)$ or medical residents $(73 \%) .{ }^{26}$

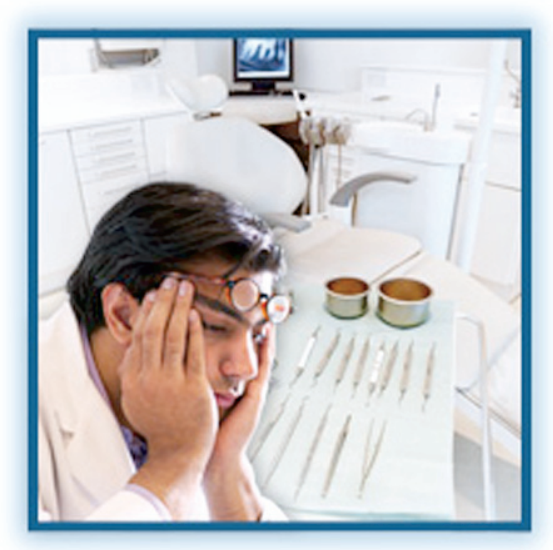

A recent cross-sectional study of dental students in the United Kingdom (UK) reported excessive alcohol consumption and illicit drug use among dental students. ${ }^{27}$ According to this study, the proportion of dental students in Newcastle drinking above the recommended low risk limits of alcohol declined from $47 \%$ as second year students, $25 \%$ as final year students, and then it increased to $41 \%$ as qualified dentists. Experimentation with illicit drugs ranged from $47 \%$ as second year students, $54 \%$ as final year students, and to $51 \%$ as dentists. The prevalence of illicit drug use in medical students was similar to dental students. Forty-seven percent of the dental student cohort as second year students, $67 \%$ as final year students, and $16 \%$ as dentists suffered from possible pathological anxiety; the proportion of dentists suffering from stress decreased from $72 \%$ as final year students to $19 \%$ as dentists. Regular tobacco use (ten or more cigarettes per day) was reported by $9 \%$ of vocational dental practitioners, with regular use being more highly reported by males (13\%) than females $(6 \%) .{ }^{28}$ The UK Dentists' Health Support Programme (DHSP) researchers are finding addiction problems among students and young dentists are increasing within all UK dental schools. ${ }^{29}$

Heavy drinking and illicit drug use are considered to be part of the youth culture today, and it seems dental students are no exception. However, excessive drinking and use of illicit drugs in young 
dentists and physicians are of concern for their own health and well being as well as the safety of patients who are under their care. The dental and medical professions have long been reluctant to acknowledge the existence of alcohol and drug abuse and stress amongst practitioners. In view of health risks associated with excessive drinking, smoking, and substance misuse, it appears further health education measures at universities are needed. ${ }^{27,30}$

This study provides some initial information on the level of tobacco and alcohol use by dental students in Romania and compares the smoking and drinking addiction between all dental school class levels.

\section{Conclusion}

Some limitations can be identified in this study. First, any change of smoking and drinking habits cannot unequivocally be attributed to the curriculum since these data were cross-sectional; they must be validated by longitudinal studies. Secondly, the school environment in this study may not be representative of other schools in Romania due to factors such as the educational setting, the nature of the training program, and geographic origin. The school in the present study is one of the national schools located in Bucharest . It is unknown whether the results will generalize to other samples. Therefore, a similar national study would need to be conducted to verify these findings.

\section{References}

1. Banoczy J, Squier C. Smoking and disease. Eur J Dent Educ. 2004; 8: 7-10.

2. Aquilino ML, Lowe JB. Approaches to tobacco control: the evidence base. Eur J Dent Educ. 2004; 8: $11-7$.

3. Kavcova E, Kocan I, Squier C. Tobacco control and the role of the medical community in the Slovak Republic. Eur J Dent Educ. 2004; 8: 46-50.

4. World Health Organization. Smoking Statistics 28 May 2002 http://www.wpro.who.int/media_centre/ fact_sheets/fs_20020528.htm

5. Peto R, Lopez AD, Boreham J, Thun M. Mortality from smoking in developed countries 1950-2000 (2ndedition, 23 August 2004). Available at: http://www.ctsu.ox.ac.uk/ tobacco/

6. Johnson NW. The role of the dental team in tobacco cessation. Eur J Dent Educ. 2004; 8: 18-24.

7. Walsh MM, Ellison JA. Treatment of tobacco use and dependence: the role of the dental professional. J Dent Educ. 2005; 69: 521-37.

8. Shelley D, Cantrell J, Faulkner D, Haviland L, Healton C, Messeri P. Physician and dentist tobacco use counseling and adolescent smoking behavior: results from the 2000 National Youth Tobacco Survey. Pediatrics. 2005; 115: 719-25.

9. Watt RG, McGlone P, Dykes J, Smith M. Barriers limiting dentists' active involvement in smoking cessation. Oral Health Prev Dent. 2004; 2: 95-102.

10. Hovell M, Roussos S, Hill L, Johnson NW, Squier C, Gyenes M. Engineering clinician leadership and success in tobacco control: recommendations for policy and practice in Hungary and Central Europe. Eur J Dent Educ.2004; 8: 51-60.

11. Piko BF, Kopp MS. Paradigm shifts in medical and dental education: behavioural sciences and behavioural medicine. Eur J Dent Educ. 2004; 8: 25-31.

12. Polychonopoulou A, Gatou T, Athanassouli T. Greek dental students' attitudes toward tobacco control programmes. Int Dent J. 2004; 54: 119-25.

13. Trinidad DR, Anderson Johnson $C$. The association between emotional intelligence and early adolescent tobacco and alcohol use. Pers Individ Dif. 2002; 32: 95-10. 2004; 197: 89-93.

14. Bergström J, Eliasson S, Dock J. Exposure to tobacco smoking and periodontal health. J Clin Periodontol. 2000; 27: 61-68.

15. Mian O, Kay EJ. A comparison of sensation-seeking between dental and biological science students. Eur J Dent Educ.2003; 7: 171- 6.

16. Myers HL, Myers LB. 'It's difficult being a dentist': stress and health in the general dental practitioner. Br Dent J. 2004; 197: 89-93. 
17. Goehring C, Bouvier Gallacchi M, Kunzi B, Bovier P. Psychosocial and professional characteristics of burnout in Swiss primary care practitioners: a cross-sectional survey. Swiss Med Wkly. 2005; 135: $101-8$.

18. Osborne D, Croucher R. Levels of burnout in general dental practitioners in the south-east of England. Br Dent J. 1994; 177: 372-7.

19. Thornton LJ, Stuart-Buttle C, Wyszynski TC, Wilson ER. Physical and psychosocial stress exposures in US dental schools: the need for expanded ergonomics training. Appl Ergon. 2004; 35: 153-7.

20. Humphris G, Blinkhorn A, Freeman R, Gorter R, Hoad-Reddick G, Murtomaa H, O'Sullivan R, Splieth C. Psychological stress in undergraduate dental students: baseline results from seven European dental schools. Eur J Dent Educ. 2002; 6: 22-9.

21. Pau AK, Croucher R. Emotional intelligence and perceived stress in dental undergraduates. J Dent Educ. 2003; 67: 1023-8.

22. Pau AK, Croucher R, Sohanpal R, Muirhead V, Seymour K. Emotional intelligence and stress coping in dental undergraduates--a qualitative study. Br Dent J. 2004; 197: 205-9.

23. Naidu RS, Adams JS, Simeon D, Persad S. Sources of stress and psychological disturbance among dental students in the West Indies. J Dent Educ. 2002; 66: 1021-30.

24. Sugiura G, Shinada K, Kawaguchi Y. Psychological well-being and perceptions of stress amongst Japanese dental students. Eur J Dent Educ. 2005; 9: 17-25.

25. Pohlmann K, Jonas I, Ruf S, Harzer W. Stress, burnout and health in the clinical period of dental education. Eur J Dent Educ. 2005; 9: 78-84.

26. Nagy K, Barabas K, Nyari T. Attitudes of Hungarian healthcare professional students to tobacco and alcohol. Eur J Dent Educ. 2004; 8: 32-5.

27. Newbury-Birch D, Lowry RJ, Kamali F. The changing patterns of drinking, illicit drug use, stress, anxiety and depression in dental students in a UK dental school: a longitudinal study. Br Dental J. 2002; 192: 646-649.

28. Underwood B, Fox K, Nixon PJ. Alcohol and drug use among vocational dental practitioners. Br Dent J. 2003; 195: 265-8.

29. Davenport PJ. Student addiction. Br Dental J. 2002; 193: 243.

30. Pine CM, McGoldrick PM. Application of behavioural sciences teaching by UK dental undergraduates. Eur J Dent Educ. 2000; 4: 49-56.

\section{About the Author}

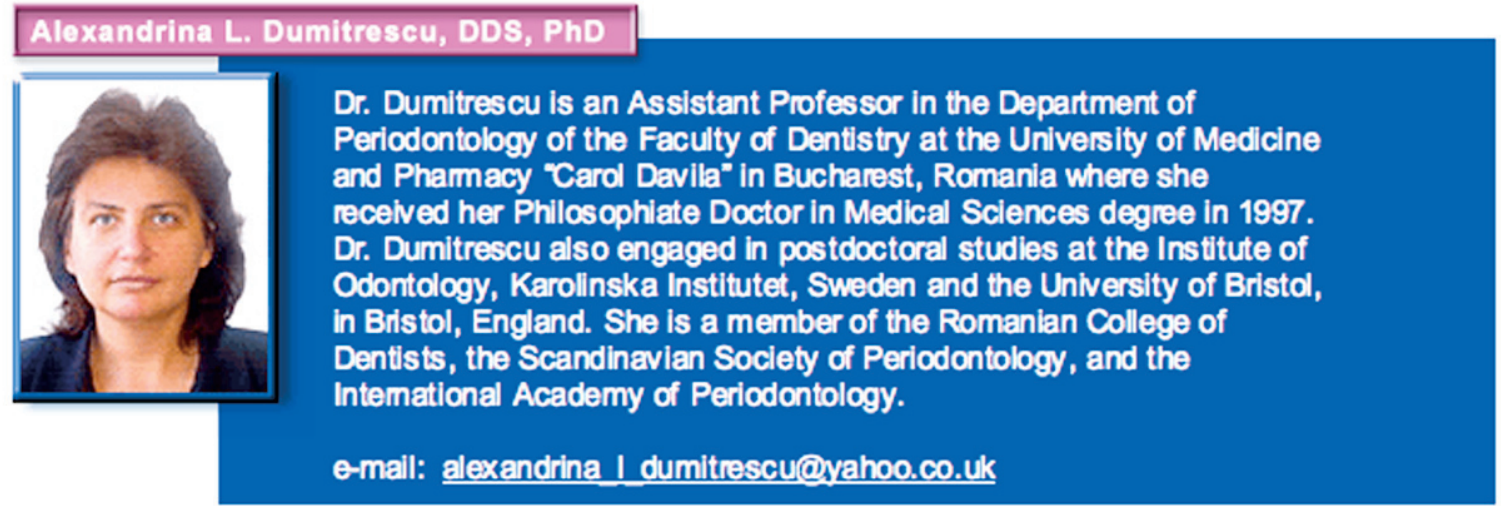

